\title{
FIRST SURFACE SOIL DRYING VALIDATION IN A PRODUCTIVE AREA IN CENTRAL ARGENTINA
}

\author{
L. Cappelletti ${ }^{1}$ *, R. Ruscica ${ }^{1}$, M. M. Salvia ${ }^{2}$, A. Sörensson ${ }^{1}$, E. Jobbágy ${ }^{3}$, N. Gattinoni ${ }^{4}$, P. Spennemann ${ }^{5}$, M. Fernandez-Long ${ }^{6}$
}

${ }^{1}$ Facultad de Ciencias Exactas y Naturales, Universidad de Buenos Aires (FCEN/UBA). Centro de Investigaciones del Mar y la Atmósfera (CIMA/UBA-CONICET). Institut Franco-Argentin d'Études sur le Climat et ses Impacts (UMI 3351-IFAECI/CNRSIRD-CONICET-UBA), IntendenteGüiraldes 2160, Ciudad Universitaria, C1428EGA, CABA, Argentina - (lucia.cappelletti, ruscica, sorensson)@cima.uba.ar

${ }^{2}$ QuantitativeRemoteSensingGroup, Instituto de Astronomía y Física del Espacio (IAFE, UBA/CONICET), Intendente Güiraldes 2160, Ciudad Universitaria, C1428EGA, CABA, Argentina-msalvia@iafe.uba.ar

${ }^{3}$ Instituto de Matemática Aplicada de San Luis, Av Ejército De Los Andes 950, San Luis (5700), Argentina - jobbagy@unsl.edu.ar

${ }^{4}$ Instituto Nacional de Tecnología Agropecuaria (INTA), Instituto de Clima y Agua, Nicolás Repetto y de los Reseros s/n (1686) Hurlingham Buenos Aires, Argentina - gattinoni.natalia@inta.gob.ar

${ }^{5}$ CONICET-Servicio Meteorológico Nacional, Av. Dorrego 4019, C1425 CABA, Argentina - pspennemann@smn.gob.ar

${ }^{6}$ Facultad de Agronomía de la Universidad de Buenos Aires (FAUBA), Av. San Martín 4453, C1417DSE, CABA, Argentina flong@agro.uba.ar

KEY WORDS: Surface Soil Moisture, dry-down time scale, SMOS, In-situ, central Argentina, seasonal analysis

\begin{abstract}
:
Surface soil moisture (SSM) dry-downs have been employed to compare independent data sources on the dynamics of water in soils, including such remote sensing, land surface models and in-situ measurements, which are often difficult to contrast with standard methodologies. The soil drying approach summarizes the soil response to climate as well as surface conditions during a dry period. In this work it is estimated as the SSM e-folding decay, named as dry-down time scale. This is the first assessment over eastern Cordoba, Argentina, a region with a very high cultivated land fraction that was subject of important agricultural changes in the last decades. SMOS SSM product (derived from microwave measurements at L band) is validated with in-situ SSM measurements provided by the National Commission for Space Activities during 2012-2018. Both products agree in showing that the austral spring season has the largest number of dry-down events for the whole period. The dry-down time scale sensitivity to the chosen detection method as well as the data sampling frequency is larger in summer than in spring. A faster soil drying in SMOS than in In-situ SSM is found, likely as a consequence of the shallower sensing depth of the first. This dependency seems to be more important than the temporal sampling frequency in the SSM data.
\end{abstract}

\section{INTRODUCTION}

Surface Soil Moisture (SSM) represents a low percentage of global water (Gleeson et al., 2015) but vastly affects energy, carbon and water balance and has an important influence on land surface energy partitioning. Thus, the knowledge of largescale soil moisture spatio-temporal dynamics is essential for various research fields such as climate and their interaction with the land surface (e.g. Seneviratne et al., 2010) or flood and drought monitoring (e.g. Liu et al., 2018)among others.

In particular, the study of soil drying or dry-down is a way of approaching soil moisture dynamics assessing in an integrated and dynamic way, the soil response to meteorological conditions, geophysical soil properties and land cover. The drydown is a dissipative process that can be quantified by the time at which the soil dries by drainage/runoff, infiltration, and evapotranspiration after a soil water input associated to irrigation, run on, raise by capillarity from groundwater or, most frequently, rainfall. Here, we study the dry-down through the surface soil moisture (SSM) spatio-temporal evolution during periods without rainfall.

Recent studies have explored the SSM dry-down approach using Land Surface Models (LSMs), Remote Sensing Products (RSPs) and In-situ measurements. They highlight that the dry- down time scale is shorter in RSPs than in ground measurements due to the difference in penetration depth (Rondinelli et al., 2015; Shellito et al., 2016), that the SSM drying is faster on sandier soils and arid regions at the global scale (McColl et al., 2017), and that it is faster in satellite data than in LSMs (Shellito et al., 2018; Piles et al., 2018). SSM dry-down studies have been implicitly taken into account for the modelling of surface water loss functions (e.g.Laio et al., 2001); now updated through RSP new data availability (Akbar et al., 2018; Jalilvand et al., 2018).

In this context, this study aims to answer the following scientific questions: 1) Is dry-down a useful framework for comparing SSM spatio-temporal dynamics of RSPs and In-situ data?; 2) How well do these two sources of SSM data agree on the dry-down time scales?; 3) Which is the main constraint to characterize SSM dry-downs?

\section{DATA}

\subsection{Study area}

The study region is located around $33^{\circ} \mathrm{S}$ of latitude and $62^{\circ} \mathrm{W}$ of longitude in the eastern Cordoba Province, Argentina (Fig.1), and it includes the Monte Buey Core Site for validation of

\footnotetext{
* Corresponding author
} 
satellite missions, like SAOCOM (see 2.2) and SMAP (NASA) (Thibeault et al., 2015).

It has a continental temperate climate, having humid summers (mean of $4.2 \mathrm{~mm} /$ day) with temperatures that reach $31^{\circ} \mathrm{C}$ in January, and drier winters (mean $<1 \mathrm{~mm} /$ day) with temperatures of $4^{\circ} \mathrm{C}$ in July. It is part of the Pampas Plains, a region with a high productivity of agriculture, cattle rising and industry, which has experienced considerable land cover change over recent decades (Salazar et al., 2015). Due to its flat topography and its latitude, it is a region with high and reliable coverage of satellite derived data. For more information about the region see Thibeault et al. (2015).

\subsection{In-situ surface soil moisture data}

Ground measurements were acquired by the Telemetric Network of Soil Moisture of the SAOCOM Mission, and provided by the National Commission for Space Activities (ComisiónNacional de ActividadesEspaciales, CONAE, Argentina, www.conae.gov.ar).

This soil moisture network consists of 66 sites and 100 sensors distributed over the Pampas region in Argentina with recording data since 2012. Hydra Probe II (Stevens ${ }^{\circledR}$ ) sensors measured the soil dielectric constant with hourly time step at different soil depths for estimating soil moisture, soil temperature and salinity. The accuracy of this sensor is $\pm 0.01 \mathrm{~m}^{3} / \mathrm{m}^{3}$. For this study, SSM volumetric $\left(\mathrm{m}^{3} / \mathrm{m}^{3}\right)$ values at a depth of $5 \mathrm{~cm}$ have been selected from 40 sensors in the eastern Cordoba Province (Figure 1). This data was aggregated at daily scale in 29 sites. The reason for having fewer sites than sensors is due to the replacement of instrumentation related to technical problems, complete breakdown or robberies. For more information about the network see Thibeault et al. (2015).

\subsection{SMOS surface soil moisture data}

The Soil Moisture Ocean Salinity mission (SMOS, 2010ongoing, Kerr et al., 2012) is dedicated to estimating surface (top $5 \mathrm{~cm}$ ) soil moisture and ocean salinity using brightness temperatures measured at L-band by the MIRAS instrument (Microwave Imaging Radiometer Aperture Synthesis, $1.4 \mathrm{GHz}$, passive microwave, ground resolution $\sim 25 \mathrm{~km}$ ). The baseline SMOS soil moisture retrieval algorithm is based on the L-MEB model (L-band microwave emission of the biosphere, Wigneron et al., 2007) and it adopts a forward modeling approach to simultaneously estimate soil moisture and vegetation optical depth. The importance of SMOS is that being an L-band radiometer, the soil emissivity is less attenuated by vegetation cover, allowing soil moisture retrievals even below moderately dense vegetation.

For this work, we used ascending passes of SMOS Soil Moisture Level 3 v. 2 daily product distributed by the Barcelona Expert Centre. This product is obtained by quality-filtering and re-gridding of the SMOS L2 data v.620: grid points affected by RFI and/or with soil moisture Data Quality Index (DQX) greater than 0.07 are discarded and a DQX-inverse weighted average is applied to bin the data from its native grid to the 25 $\mathrm{km}$ EASE2 equal-area grid. Data and further details are available at http://cp34-bec.cmima.csic.es/.

Figure 1 shows the chosen SMOS grid-cells as Pixel2, Pixel4, etc. (yellow pins), selected for sharing location with the in-situ data. The period of analysis begins in 2012 due to availability of in-situ data and finishes at the end of 2018.

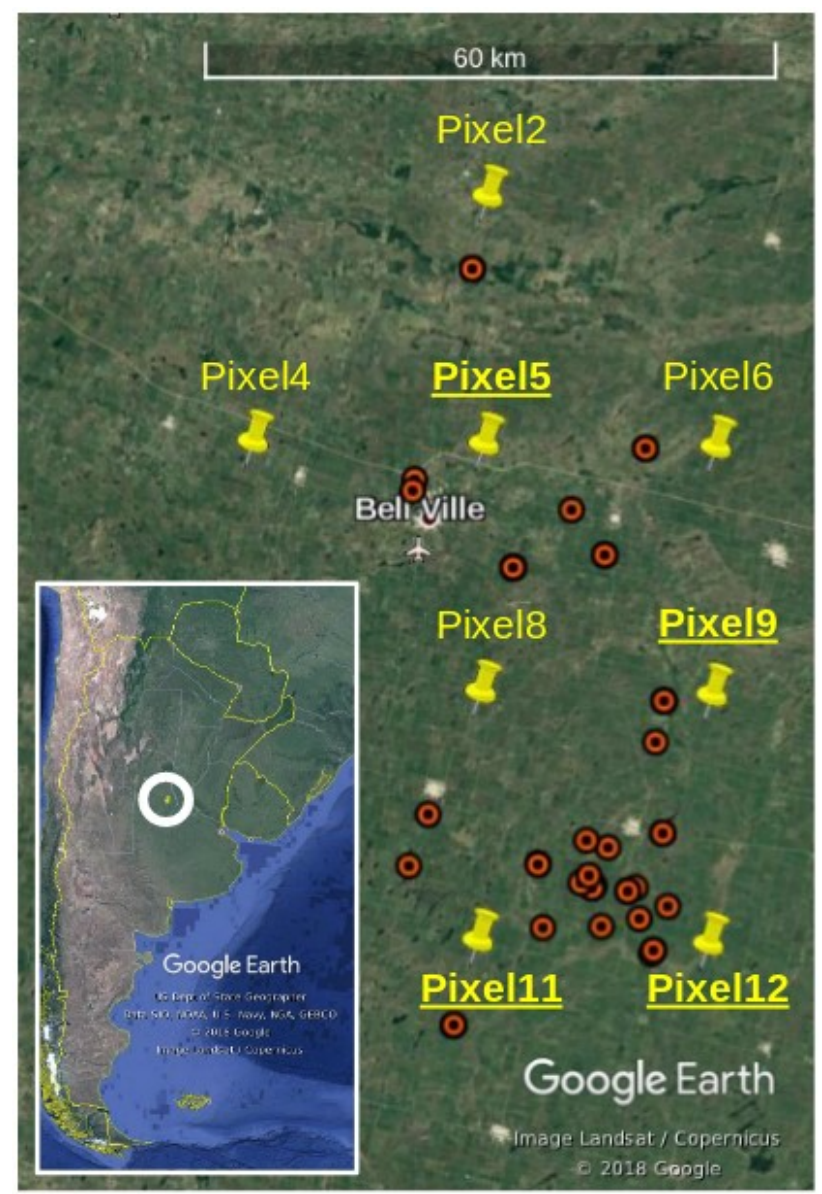

Figure 1. Region of study in central Argentina (white circle in the inserted map). Soil moisture sensors and chosen SMOS grid cells are indicated by red-black circles and yellow pins with assigned names respectively. Bold and underlined SMOS names highlight those grid points with the higher number of sensors.

\section{METHODS}

The following methods were applied for each season separately, namely DJF (1st December to 28th February) for austral summer, MAM (1st March to 31st May) for austral autumn, JJA (1st June to 31st August) for austral winter and SON (1st September to 30th November) for austral spring, from 2012 to 2018. When annual values are shown they are the addition of seasonal ones.

We are aware of the complexity that exists between the spatial behaviour of the SMOS footprint and single in-situ measurements. In this work, we decided not to get a unique representative soil moisture time series per SMOS pixel because (1) we want to get a $\boldsymbol{\tau}$ statistical analysis per pixel but (2) mainly because the spatial average among soil moisture time series would reduce the variability which could lead to a nonexponential evolution in the drydown process.

\subsection{Dry-down detection}

We have used positive increments in the SSM time series as a proxy for water input to the system. For SMOS, we defined a dry-down as an event starting on a day when there is a SSM 
increase of at least $0.1 \mathrm{~m}^{3} / \mathrm{m}^{3}(2.5$ times the product target accuracy) between two consecutive SSM estimates and ending when there is an increase of SSM larger than $0.04 \mathrm{~m}^{3} / \mathrm{m}^{3}$ (product target accuracy).

For in-situ data, the dry-down start is also $0.1 \mathrm{~m}^{3} / \mathrm{m}^{3}$, but ends when an increase larger than $0 \mathrm{~m}^{3} / \mathrm{m}^{3}$ occurs (hereafter In-situ database). For studying the influence that the detection method and the sampling frequency have on results, we created a new data series where the in-situ data was resampled by SMOS data availability. Dry-down detection in this new data series was carried out using both 0 (In-situ_mSMOS) and $0.04 \mathrm{~m}^{3} / \mathrm{m}^{3}$ (Insitu_mSMOS_004) as ending conditions.

Resulting dry-downs of less than 5 days long and/or with less than 4 SSM values were excluded from the analysis in all databases.

As an example, Figure 2 shows some dry-downs in 3 SMOS pixels. Although the dynamic ranges are different (larger in SMOS) both products tend to detect the same dry-downs in 3 different periods, with SMOS having a dry bias in 2 of them. This dry bias was also seen in Thibeault et al. (2015).

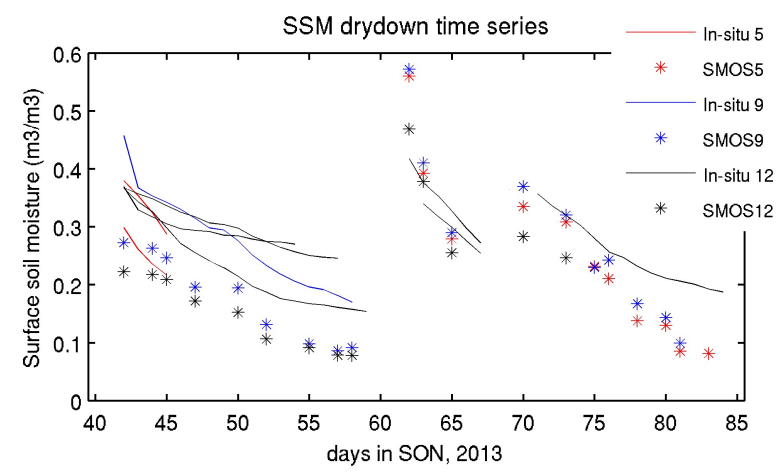

Figure 2. Surface soil moisture (SSM) dry-downs for In-situ (full line) and SMOS $\left(^{*}\right)$ data, during SON 2013. In-situ /

SMOS 5, 9 and 12 refers to all in-situ /SMOS SSM dry-downs within Pixel5, Pixel9 and Pixel12 respectively.

\subsection{Modelling methodology}

SSM dry-down has been modeled by a decreasing exponential function since the 80`s (Delworth, Manabe, 1988). Recent studies have used this approach for modeling SSM dry-down in RSPs (Rondinelli et al., 2015; Shellito et al., 2016), and it has been suggested that this exponential model is correct on waterlimited soil conditions or stage-II (McColl et al., 2017; Shellito et al., 2018). During the dry-down the SSM can be modeled by the following equation

$$
\operatorname{SSM}(t)=A * \exp (-t / \tau)+S M_{f}
$$

where $\quad A=$ amplitude of the dry-down $\left(\mathrm{m}^{3} / \mathrm{m}^{3}\right)$

$\mathrm{t}=$ time since the beginning of the dry-down (days)

$\boldsymbol{\tau}=$ dry-down time scale (days) and

$\mathrm{SSMf}=$ equilibrium value $\left(\mathrm{m}^{3} / \mathrm{m}^{3}\right)$

In this work, we just focused on the dry-down time scale as an indicator of top soil drying velocity, although its unit is given in days. Large $\boldsymbol{\tau}$ values refer to slow soil drying and small $\boldsymbol{\tau}$ values refer to fast drying. For each detected SSM dry-down, we applied a nonlinear curve-fitting to find the parameters that best fit the data to equation 1 (in a least-squares sense) using a subspace trust-region method based on the interior-reflective
Newton method (e.g. Coleman and Li, 1996). We also constrained the fitting parameters to avoid spurious values: SSMf has to be lower than the lowest soil moisture value observed during the dry-down and $\boldsymbol{\tau}$ values must not be larger than the length of a season (90 days)

For each SMOS pixel and season we got a distribution of $\boldsymbol{\tau}$ values obtained for all years. Left column of Table 1 shows the analyzed SMOS pixels together with the amount of in-situ sites embedded in it (in parenthesis). Therefore, in-situ $\boldsymbol{\tau}$ distributions also include the spatial variability among sites in each of the analyzed pixels.

\section{RESULTS AND DISCUSSION}

\subsection{Number of seasonal dry-down events}

Table 1 shows the amount of in-situ and SMOS dry-down events which have an associated $\boldsymbol{\tau}$, taking into account the influence of the sampling frequency and the dry-down detection method. This amount is given per season and for the whole period (columns), per SMOS pixel (rows) and per dataset in the following order: In-situ, In-situ_mSMOS, In-situ_mSMOS_004 and SMOS. As expected, there are more dry-down events where there are more in-situ sites as in the case of Pixel5, Pixel9, Pixel11 and mostly in Pixel12 where the Monte Buey validation core site is located (see section 2.1)

\begin{tabular}{|c|c|c|c|c|c|}
\hline $\begin{array}{c}\text { Pixel names } \\
\text { (\#IDs) }\end{array}$ & DJF & MAM & JJA & SON & Annual \\
\hline Pixel2 (1) & $1,2,2,0$ & $2,3,3,0$ & $2,1,1,3$ & $5,6,6,11$ & $10,12,12,14$ \\
\hline Pixel4 (1) & $1,0,1,6$ & $2,2,2,0$ & $2,1,1,1$ & $7,7,9,9$ & $12,10,13,16$ \\
\hline Pixel5 (5) & $7,12,14,3$ & $8,8,8,6$ & $11,7,6,4$ & $19,18,19,13$ & $\mathbf{4 5 , 4 5 , 4 7 , 2 6}$ \\
\hline Pixel6 (2) & $1,2,2,9$ & $4,1,1,4$ & $5,2,2,2$ & $6,2,2,14$ & $16,7,7,29$ \\
\hline Pixel8 (1) & $0,0,0,6$ & $1,2,3,5$ & $1,0,0,3$ & $2,3,4,8$ & $4,5,7,22$ \\
\hline Pixel9 (4) & $5,3,3,5$ & $7,10,11,3$ & $10,7,6,0$ & $18,12,13,17$ & $\mathbf{4 0 , 3 2 , 3 3 , 2 5}$ \\
\hline Pixel11 (5) & $10,10,12,9$ & $14,7,9,2$ & $15,3,2,1$ & $19,7,7,9$ & $\mathbf{5 8 , 2 7 , 3 0 , 2 1}$ \\
\hline Pixel12 (10) & $21,13,17,9$ & $29,16,26,1$ & $\mathbf{3 1}, 8,9,0$ & $\mathbf{3 6 , 2 7 , 3 1 , 1 4}$ & $\mathbf{1 1 7 , 6 4 , 8 3 , 2 4}$ \\
\hline
\end{tabular}

Table 1. Number of dry-down events for each SMOS pixel, season and the whole period (name as annual) in the following order: In-situ, In-situ_mSMOS, In-situ_mSMOS_004 and

SMOS. Numbers between brackets are the amount of in-situ sites embedded in each SMOS pixel. In bold are values larger or equal than 30 .

When In-situ data is resampled temporally by SMOS data availability, the amount of dry-down events should be reduced since there are less data leading to poor $\boldsymbol{\tau}$ estimates. This is the case of the JJA winter season where dry-downs are usually long due to less water atmospheric demand. However, DJF and MAM, and in lesser degree SON, show some grid points where the behaviour is the opposite. This is explained by the fact that resampling eliminates some possible dry-downs (not satisfying conditions in 3.1 and 3.2) but adds others when these drydowns have short to intermediate lengths (Ruscica et al., submitted).

A less restrictive dry-down detection method should result in the same or a higher amount of number of events. Looking at In-situ_mSMOS and In-situ_mSMOS_004 values this is what happens in most of the cases in SON. However, DJF and MAM 
and mostly JJA do not show a clear behaviour. This is probably due to the small size of samples.

In a seasonal analysis, SON stood out as the season where SSM dry-downs are more prone to occur over almost all pixels (Table 1). MAM and JJA on the other hand are seasons with fewer drydown events in SMOS and in consequence they will be discarded from the following analysis. Pixel5 and Pixel9 will not be analyzed in DJF for the same reason.

\subsection{In-situ surface soil drying estimates}

Through equation (1) we obtained the dry-down time scale or $\boldsymbol{\tau}$ with large (small) values referring to slow (fast) soil drying. Figures $3 \mathrm{a}$ and $3 \mathrm{~b}$ show the $\tau$ distribution for DJF and SON respectively. There are 4 boxplots per panel which, from left to right, summarize the In-situ (1st), In-situ mSMOS (2nd), Insitu_mSMOS_004 (3rd) and SMOS (4th) $\boldsymbol{\tau}$ distributions.

In general, we can see an asymmetric behavior around the median, with a long upper tail and most of the events concentrated within smaller values, indicating a positive skewness in the distributions. This pattern was also found in other studies (McColl et al., 2017, Ruscica et al., submitted).

Comparing seasons, DJF shows stronger differences among the 4 datasets than SON.

4.2.1 Influence of SMOS's sampling frequency: The comparison between In-situ (1st) and In-situ_mSMOS (2nd) boxplots allows us to estimate how much the soil drying detected by the SSM ground measurements is modified for having a non-daily temporal resolution, i.e. in this case given by SMOS available data.

SON does not show a clear result in the median $\boldsymbol{\tau}$ since the two western grid cells show lower values with resampling and the two eastern grid cells show the opposite effect. In addition, this is not explained by the number of events since it diminishes in all grid cells. However, we can clearly observe a larger interquartile range (IQR) and extremes for resampled data, suggesting that a SSM temporal resolution lower than a day increases the uncertainty in $\boldsymbol{\tau}$ estimates.

DJF on the other hand, shows that resampling tends to reduce the soil drying velocity giving larger median $\boldsymbol{\tau}$ values, although the difference is just marked for Pixel11. Contrary to SON, resampled data show here a smaller IQR than daily one.

4.2.2 Influence of dry-down detection method: The comparison between In-situ_mSMOS (2nd) and Insitu_mSMOS_004 (3rd) boxplots is done to quantify how much the $\overline{\boldsymbol{\tau}}$ estimates depend on the dry-down ending criteria, that is usually related to the measurement error (section 3.1).

As expected, a less restrictive dry-down end criteria (0.04 instead of $0 \mathrm{~m}^{3} / \mathrm{m}^{3}$ ) results in a larger IQR and longer whiskers tails in the distributions in both seasons. Basically, it includes dry-down events - or adds more days to the ones already included - with small increases of SSM, changing the exponential model parameters.

SON boxplots show that there is less difference among these $\tau$ distributions (median, IQR and extremes) than those seen in the previous section regarding resampling. 3a) DJF
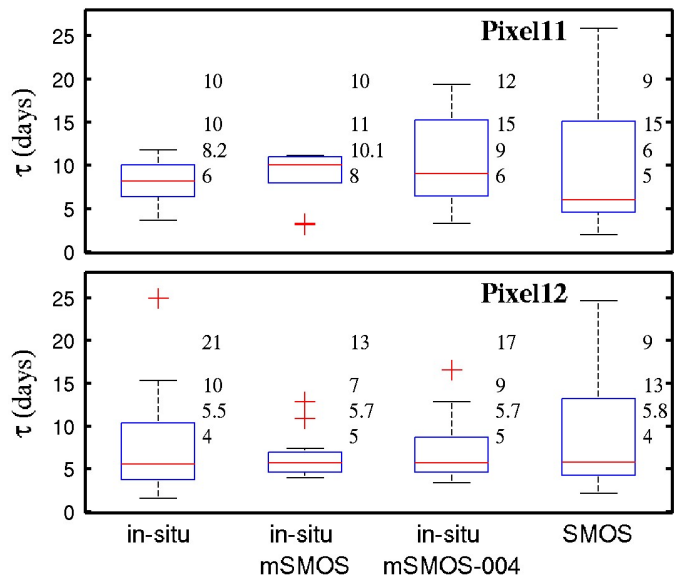

3b) $\mathrm{SON}$
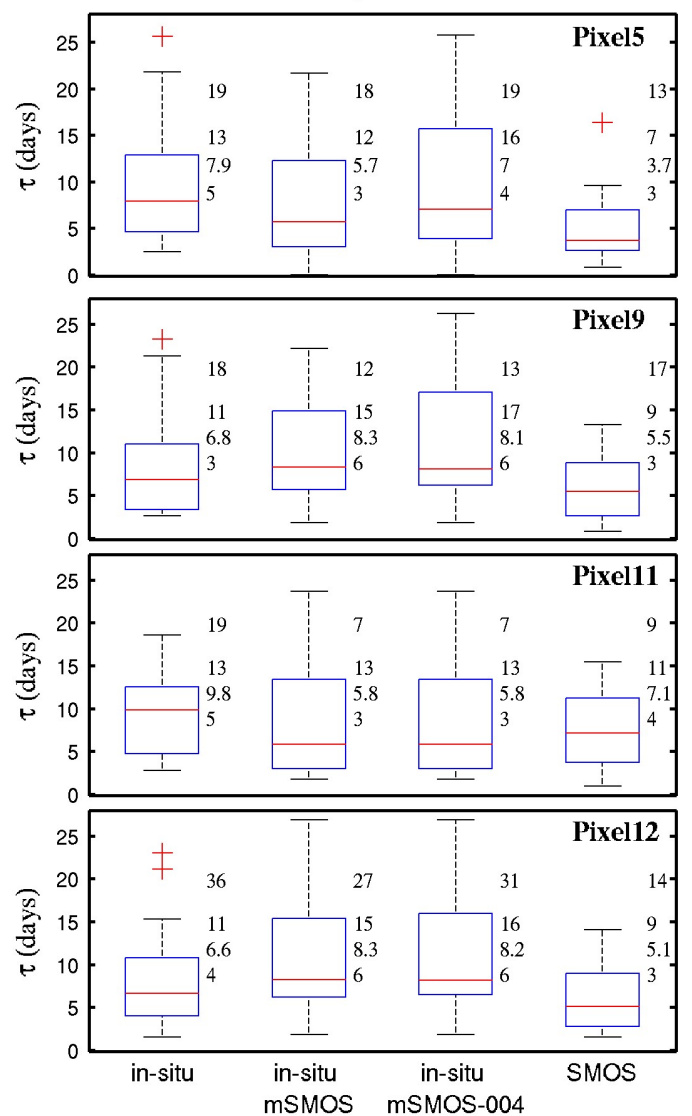

Figure 3. Dry-down time scale $(\boldsymbol{\tau})$ distributions in Pixel1 1 and Pixel12 in DJF (Fig.3a) and Pixel5, Pixe19, Pixel11 and Pixel12 in SON (Fig.3b), for In-situ (1st), In-situ mSMOS (2nd), Insitu_mSMOS_004 (3rd) and SMOS (4th) in 4 selected SMOS pixels. Median and IQR values are represented by the red line and the blue box respectively. Numbers close to each boxplot

show (from top to bottom): number of drydown events, percentiles 75, 50 (median) and 25 of each distribution.

For DJF, we can see the same effect over the median $\boldsymbol{\tau}$ values, however, this is not so clear for IQR. For IQR we can see that Pixel11 shows a larger difference between In-situ_mSMOS and In-situ_mSMOS_004 than between In-situ and Insitu_mSMOS, but for Pixel12 it is the other way around. 


\subsection{Validation of surface soil drying estimates}

How comparable are SMOS' and CONAE's SSM dry-down estimates? In-situ mSMOS_004 (3rd) and SMOS (4th) boxplots in Fig. 3 have to be compared in order to correctly answer that question since they share the sampling frequency and detection method. We can see a different relationship between these datasets in SON and DJF. SMOS $\tau$ distributions are much thinner (wider) than in-situ mSMOS 004 in SON (DJF). This can be due to the effect that resampling has on insitu data in SON (section 4.2.1) or that SMOS soil drying in summer is more uncertain that in spring.

However, both seasons show that most of the pixels show smaller median $\boldsymbol{\tau}$ values in SMOS than in the rest of the datasets. In other words, the soil as seen by the satellite dries faster than as measured by in-situ probes as other studies have shown (Rondinelli et al., 2015; Shellito et al., 2016). The most likely cause of this result is the effective depth analyzed with each approach. In-situ probes are installed $5 \mathrm{~cm}$ beneath the soil surface, and sense a volume of 1 litre (1L.) around them, making the effective sensing depth approximately between 3 and $7 \mathrm{~cm}$., whilst microwave sensors measure the very top soil radiation emission up to $5 \mathrm{~cm}$, and their sensing depth is dependent on soil water content, i.e. sensing depth is reduced when soil water content increases.

\section{CONCLUSIONS}

Soil moisture dynamics knowledge is important for improving weather forecasts, drought and climate predictions amongst other applications. In this study, we focused on the decreasing exponential dry-down approach where we estimated the time at which the soil gets dry (defined as $\tau$ dry-down time scale), during a period with no rainfall. An advantage of the time scale approach lies in its independency of SSM absolute values or any reference value as other metrics do (e.g. autocorrelation time scale, Koster and Suarez (2001)) and it should be not affected by rescaling or bias correction methods.

Surface soil moisture (SSM) data was taken from SMOS L band satellite product and from CONAE's Telemetric Network of Soil Moisture of the SAOCOM Mission, during 2012-2018. Both products agree that the austral spring (SON) has the largest number of dry-down events. We have found that SMOS has a small amount of dry-down events in MAM and JJA seasons, but for different reasons (not shown). In JJA, SMOS SSM time series did not satisfy the detection methodology conditions. On the other hand, MAM SSM time series did satisfy the detection methodology, obtaining dry-down events, however, most of them did not result in a good fit to the exponential decay model. As a consequence, for future studies, we should extend the period of analysis, incorporate other satellite information and/or define a different detection methodology.

A faster soil drying in SMOS than in in-situ observations was found as a consequence of a shallower sensed depth in satellites (Rondinelli et al., 2015; Shellito et al., 2016). This result is independent on taking sampling frequency into account or not. This first assessment of in-situ dry-downs will complement the work of Ruscica et al. (submitted) where several satellite products and a land surface model were used for the dry-down exploration at a regional scale over southeastern South America.
In parallel to this work, we are exploring how reliable is the use of $\boldsymbol{\tau}$ as an indicator of flooding, since land surface would dry slower under flooded conditions.

\section{ACKNOWLEDGEMENTS}

This work was supported by the AgenciaNacional de PromociónCientífica y Tecnológica (ANPCyT) projects PICT 2017-1406 and 2015-3097 and the International InterAmerican Institute for Global Change Research (IAI) CRN 3035, which is supported by the U.S. National Science Foundation] under Grant [GEO-1128040]. SMOS SM data are freely available at BEC website: http://cp34-bec.cmima.csic.es/. The authors wish to thank CONAE for kindly providing the insitu SSM data.

\section{REFERENCES}

Akbar, R., Short Gianotti, D.J., McColl, K.A., Haghighi, E., Salvucci, G.D., Entekhabi, D., 2018. Estimation of Landscape Soil Water Losses from Satellite Observations of Soil Moisture. J. Hydrometeor. 19, 871- 889 .

Coleman, T.F. and Li, Y., 1996. An Interior, Trust Region Approach for Nonlinear Minimization Subject to Bounds. SIAM J. Optim. 6, 418-445.

Delworth, T. L., and S. Manabe, 1988. The influence of potential evaporation on the variabilities of simulated soil wetness and climate. J. Clim. 1 (5): 523-547.

Dirmeyer, P.A. and Halder, S., 2016. Sensitivity of Numerical Weather Forecasts to Initial Soil Moisture Variations in CFSv2. Wea.Forecasting. 31, 1973-1983.

Gleeson, T., Befus, K.M., Jasechko, S., Luijendijk, E., Cardenas, M.B., 2015. The global volume and distribution of modern groundwater. Nat. Geosci. 9, 161-167.

Jalilvand, E., Tajrishy, M., Brocca, L., Massari, C., Hashemi, S.G.Z., Ciabatta, L., 2018.Estimating the drainage rate from surface soil moisture dry-downs: application of DfD model to in situ soil moisture data. J. Hydrol. 565, 489-501.

Kerr, Y.H., Waldteufel, P., Richaume, P., Wigneron, J.P., Ferrazzoli, P., Mahmoodi, A., Al Bitar, A., Cabot, F., Gruhier, C., EnacheJuglea, S., Leroux, D., Mialon, A., Delwart, S. 2012. The SMOS soil moisture retrieval algorithm. IEEE Trans. Geosci. Remote Sens., 50(5), 1384-1403.

Koster, R.D. and M.J. Suarez, 2001.Soil Moisture Memory in Climate Models.J. Hydrometeor. 2 (6): 558-570.

Laio, F., Porporato, A., Ridolfi, L, Rodriguez-Iturbe, I., 2001. Plants in water-controlled ecosystems: Active role in hydrologic processes and response to water stress: II. Probabilistic soil moisture dynamics. Adv. Water Resour. 24(7), 707-723.

Liu, Y., Liu, Y., Wang, W., 2018. Inter-comparison of satelliteretrieved and Global Land Data Assimilation System-simulated soil moisture datasets for global drought analysis.Remote Sens. Environ. 220,1-18.

McColl, K.A., Wang, W., Peng, B., Akbar, R., Short Gianotti, D.J., Lu, H., Pan, M., Entekhabi, D., 2017.Global 
characterization of surface soil moisture dry-downs.Geophys. Res. Lett. 44, 3682-3690.

Piles, M., van der Schalie,R., Gruber, A., Muñoz-Marí, J., Camps-Valls, G., Mateo-Sanchis, A., Dorigo, W., de Jeu, R., 2018. Global Estimation of Soil Moisture Persistence with L and C-Band Microwave Sensors. IGARSS-2018 2018 IEEE International Geoscience and Remote Sensing Symposium, Valencia. pp. 8259-8262.

Rondinelli, W.J., Hornbuckle, B.K., Patton, J.C., 2015. Different Rates of Soil Drying after Rainfall Are Observed by the SMOS Satellite and the South Fork In Situ Soil Moisture Network. J. Hydrometeor. 16, 889-903.

Ruscica, R., Polcher, J., Salvia, M., Sörensson, A., Piles, Karszenbaum, H., Jobbágy, E. Spatio-temporal soil drying in southeastern South America: the importance of the effective sampling frequency and observational errors on drydown time scale estimates. Submitted to Int. J. Remote Sens. 9 Nov, 2019.

Salazar, A., Baldi, G., Hirota, M., Syktus, J., McAlpine, C., 2015. Land use and land cover change impacts on the regional climate of non-Amazonian South America: A review. Glob.Planet. Change 128: 103-119.

Seneviratne, S.I., Corti, T., Davin, E.L., Hirschi, M., Jaeger, E.B., Lehner, I., Orlowsky, B., Teuling, A.J., 2010.Investigating soil moisture climate interactions in a changing climate: A review. Earth-Sci. Rev. 99 (3-4), 125-161.

Shellito, P.J., Small, E.E., Colliander, A., Bindlish, R., Cosh, M.C., Berg, A.A., Bosch, D.D., Caldwell, T.G., Goodrich, D.C., McNairn, H., Prueger, J.H., Starks, P.J., van der Velde, R., Walker, J.P., 2016. SMAP soil moisture drying more rapid than observed in situ following rainfall events.Geophys. Res. Lett. $43,8068-8075$.

Shellito, P.J., Small, E.E., Livneh, B., 2018. Controls on surface soil drying rates observed by SMAP and simulated by the Noah land surface model. Hydrol. Earth Syst. Sci. 22, 1649-1663.

Thibeault, M., Caceres, J, Dadamia, D., Soldano, A., UriburuQuirno, M., Guerrieri, J., Edrosa, R., Palomeque, M., Romaldi, L., Pucheta, J., Luca, E., Bustos, S., Aguero, S., Pascual, I., Mariotti, M. Spatial and temporal analysis of the Monte Buey SAOCOM and SMAP core site. 969-971. IGARSS-2015 2015 IEEE International Geoscience and Remote Sensing Symposium. 10.1109/IGARSS.2015.7325929.

Wigneron, J.P., Kerr, Y., Waldteufel, P., Saleh, K., Escorihuela, M. J., Richaume, P., Ferrazzoli, P., de Rosnay, P., Gurney, R., Calvet, J.C., Grant, J.P., Guglielmetti, M., Hornbuckle, B., Mätzler, C., Pellarin, T., Schwank, M., 2007. L-band Microwave Emission of the Biosphere (L-MEB) Model: Description and calibration against experimental data sets over crop fields. Remote Sens. Environ. 107, 639-655. 